\title{
LA INFLUENCIA DEL IUSNATURALISMO RACIONALISTA EN LA GÉNESIS DE LA MORAL CRISTIANA POS-EVANGÉLICA
}

\author{
Fernando H. Llano Alonso \\ Universidad de Sevilla
}

\section{RESUMEN}

En el presente artículo se pretende realizar un análisis en términos prospectivos de las principales claves e interrogantes suscitados a propósito de una de las más enigmáticas fases de la historia de la filosofía clásica: la génesis de la moral cristiana pos-evangélica, en donde pueden hallarse vínculos indisolubles en la tradición iusnaturalista greco-romana.

Palabras clave: iusnaturalismo, moral, evangélico

\begin{abstract}
The influence of the rationalistic iusnatualism in the genesis of the post-evangelical Christian moral. This essay tries to present an analysis in prospective terms of the main keys and questions risen from one of the most eningmatic stages in the history of classical philosophy: the genesis of post-evangelical christian morality in which it is possible to find indissoluble bonds with the iusnaturalist greco-latin tradition.
\end{abstract}

Key words: iusnaturalism, moral, evangelic.

\section{PLANTEAMIENTO INICIAL}

A nivel historiográfico, una de las principales fuentes de controversia en los foros de debate iusfilosófico ha sido tradicionalmente la defensa de una teoría que afirma la manifiesta continuidad de la corriente iusnaturalista-racionalista en el decurso de los siglos, desde la Antigüedad grecoromana, pasando por la patrística y la escolástica, hasta el racionalismo de los siglos XVII-XVIII, en el que se sentaron las bases del moderno Estado de Derecho. ${ }^{1}$

1 G. Fassò, La legge della ragione, Bolonia, Il Mulino, 1966 (2. ${ }^{\text {a }}$ ed.); Storia della Filosofia del Diritto (vol. I: Antichità e Medioevo), Bolonia, Il Mulino, 1974 (3. ${ }^{a}$ ed.), p. 11 [trad. cast., J.F. Lorca Navarrete, Madrid, Pirámide, 1982 (3. ${ }^{a}$ ed.)]; F.H. Llano Alonso, «Guido Fassò: articulation of the law and jurisprudence within a plural concept of sources», European Journal of Law; Philosophy and Computer Science, vol. V (1995), pp. 8 y ss.; «Recensión al libro de Dario Quaglio», Anuario de Filosofía del Derecho (1994), pp. 680 y ss. 
Contra esta teoría se han alzado habitualmente las voces discrepantes de aquellos que defienden la existencia de una ineludible fractura entre el mundo clásico y el contemporáneo, representando el período medieval un paréntesis «subjetivo» que contribuyó a retrasar la maduración de la modernidad. De otro lado se sitúan quienes, fundándose en el tradicional esquema idealista-espiritualista-modernista, sostienen que frente a la etapa antigua de la filosofía occidental, donde el hombre se integraba pasivamente en el orden natural, esto es, en la realidad «objetiva», el cristianismo supuso el descubrimiento del individuo como sujeto dotado de autonomía y espíritu, hundiendo en esta época sus raíces la cultura moderna, la cual, tras depurar el objetivismo que durante el Medievo se había infiltrado en el pensamiento cristiano, reverdecería vigorosamente a partir del Renacimiento. ${ }^{2}$

Frente a esta perspectiva idealista de la historia, y en abierta oposición a cualquier interpretación antihistórica del iusnaturalismo, hubo autores, como Guido Fassò, Rodolfo Mondolfo o Werner Jaeger, cuyas tesis denunciarían la inviabilidad de toda tentativa doctrinal que estuviese dispuesta a vincular el mundo greco-romano con una ética naturalista, o el cristianismo con la moral subjetiva moderna, porque, si bien es cierto que en la Antigüedad clásica se concebía a la physis como un todo armónico y objetivo, no debe obviarse que a ese orden se incorporaba el hombre como criatura racional, produciéndose una transposición de conceptos inherentes al ser humano, desde la esfera individual al universo natural. Del mismo modo, el subjetivismo cristiano tenía un carácter místico, admitiendo la subjetividad de los hombres tan sólo como participación en el Valor divino y, por consiguiente, trascendiendo la propia humanidad relativa e histórica. ${ }^{3}$

En opinión de Fassò, la idea de modernidad sólo podía guardar relación con una ética subjetiva que estuviera en consonancia con el racionalismo, ya que era en él donde había fermentado el pensamiento contemporáneo; es más, añadía el profesor boloñés, «[...]se la storia del razionalismo [...] noi la consideriamo nel particolare dominio dell'etica, la vedremo pressoché identificarsi con la storia del giusnaturalismo». ${ }^{4}$

Así pues, en opinión de este pensador, la ética moderna era la resultante de la íntima correlación existente entre el subjetivismo y el racionalismo; por tanto, sólo desde un planteamiento homogéneo de la evolución histórica iusfilosófica que ponderase las principales aportaciones que en cada época se habían realizado para la cristalización de este concepto, podría accederse a una comprensión integral de los problemas y cuestiones que a lo largo de los siglos han venido aquejando a la Filosofía del Derecho.

2 E. Zeller, Die Philosophie der Griechen in ihrer geschichtlichen Entwicklung; trad. it., R. Mondolfo, parte I, vol. I, Florencia, La Nuova Italia, 1932, p. 293.

3 Ibidem, pp. 306-355; R. Mondolfo, La comprensione del soggetto umano nell'antichità classica, Florencia, La

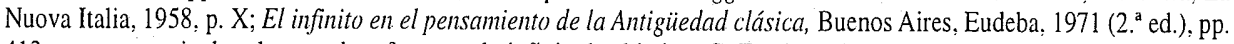
413 y ss., en particular el apartado referente a la infinitud subjetiva; G. Fassò, «Diritto e morale nel pensiero greco», en Scritti di Filosofia del Diritto (II), p. 793; Storia della Filosofia del Diritto (I), p. 138; W. Jaeger, Alabanza de la ley: Los orígenes de la Filosofía del Derecho y los griegos, trad. cast., A. Truyol y Serra, Madrid, Centro de Estudios Constitucionales, 1982 (2." de.), pp. 22-25; Paideia. Die Formung des griechischen Menschen; trad. cast., J. Xirau y W. Roces, Madrid, Fondo de Cultura Económica, 1981; A. Truyol y Serra, Historia de la Filosofía del Derecho (de los origenes a la Edad Media), Madrid, Revista de Occidente, 1970 (4. ${ }^{\text {a }}$ ed.). pp. 119-120. A favor de un esquema idealista y preconcebido de la historia de la Filosofía del Derecho, vid. G. Gentile, Sistema di logica come teoria del conoscere,

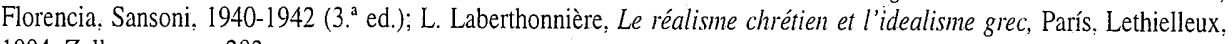
1904; Zeller; o.c., pp. 282 y ss.

4 Fassò, La legge della ragione, p. 15. 


\section{LA PRESENCIA DEL IUSNATURALISMO RACIONALISTA EN LA PATRÍSTICA Y EN SAN AGUSTÍN}

El período cronológico comprendido entre la época clásica y los albores del Medievo arroja datos de indiscutible trascendencia para cualquier investigador de la historia de la filosofía medieval, ya que de ellos se nutrirán sus principales conclusiones teóricas. ${ }^{5}$

Si bien es cierto que durante buena parte del presente siglo el Derecho natural ha formado parte de la moral católica, hasta el punto de que muchos - como en el caso de Maritain - ${ }^{6}$ coincidían al relacionar el iusnaturalismo «cristiano» con aquel otro de estirpe estoico-ciceroniana, no debe soslayarse el hecho de que, para otros autores, esta circunstancia obedecía a la cristalización de un proceso viciado mediante el cual, con el transcurso del tiempo, las genuinas señas de identidad de la ética cristiana se diluían a medida que se iban filtrando restos de lo que en su día constituyó la veta racionalista del iusnaturalismo antiguo, produciéndose finalmente una auténtica simbiosis entre ambas concepciones.

Inicialmente el cristianismo representó un movimiento que, como indicaba Battaglia, no sólo se circunscribía al terreno de la moral, sino que también afectaba al área de lo jurídico-político, habida cuenta del enfrentamiento que en un principio sostuvieron los cristianos con el Imperio romano - al negarse a reconocer la sacralidad del césar por atentar contra los principios y las convicciones más elementales de su religión monoteísta. Por tanto, no debe extrañar que tanto la justicia como el Derecho fueran concebidos de forma diversa en los Evangelios y, sobre todo, por parte de san Pablo en sus Epístolas, ${ }^{7}$ en particular la que está dedicada a los romanos, donde existe un fragmento en el que reprocha a los israelitas su dependencia de una ley divina revelada, siendo superados por los gentiles (los demás pueblos) que, sin conocer la ley mosaica, obraban adecuándose a ella movidos por la naturaleza, al mismo tiempo que llevaban escrita en el corazón su propia ley, correspondiéndose así ambas normativas: la mosaica de los judíos con la natural de los gentiles. $^{8}$

En cualquier caso, la tergiversación de este pasaje paulino junto a la gradual juridificación de la sociedad cristiana y la penetración de la teoría estoica sobre la ley natural universal —entendida como summa ratio- ${ }^{9}$ en el cristianismo pos-evangélico de la patrística, explicaban la fácil asimilación del iusnaturalismo racionalista greco-romano por parte de los Padres de la Iglesia. Este sincretismo tenía su precedente inmediato en la convergencia que el legalismo hebreo presentaba res-

5 Fassò.Storia della Filosofia del Diritto (I). p. 141; «La legge della ragione», en Scritti di Filosofia del Diritto (II), p. 747; «Sant'Agostino e il giusnaturalismo cristiano», en Scritti di Filosofia del Diritto (II). p. 751. Cfr., G. Ambrosetti, Lezioni di Filosofia del Diritto. Tra metafisica classica e filosofia dei valori: il senso del diritto, Roma, Studium, 1965, p. 259.

6 J. Maritain, Les droits de l'homme et la loi naturelle, París, Hartmann-E. Aulard, 1947, pp. 62-63; S. Cotta, La città politica di Sant'Agostino, Milán, Comunità, 1960, p. 17.

7 G. Del Vecchio, Lezioni di Filosufia del Diritto, Roma, Rivista Internazionale di Filosofia del Diritto, 1936 (3. ${ }^{2}$ ed.), p. 44; F. Battaglia, Corso di Filosofia del Diritto (I), Roma, Soc. Ed. del «Foro Italiano», 1960, p. 188 [trad. cast., F. Elías de Tejada y P. Lucas Verdú, Madrid, Ed. Reus, 1951]; G. Solari, La formazione storica e filosofica dello stato moderno, Turín, Giappichelli, 1962, pp. 23 y ss.; E. Opocher, Lezioni di Filosofia del Diritto, Padua, Cedam, 1993 (2. ${ }^{\text {a ed.), p. }}$ 86.

8 San Pablo, Rom., II, 14-15.

9 Fassò, Storia della Filosofia del Diritto (I), p. 141; R. Treves, Lezioni di Filosufia del Diritto, Milán, La Goliardica, 1969, p. 20. 
pecto al racionalismo griego, siendo Filón de Alejandría la figura más relevante de este período histórico de la Filosofía del Derecho.

La identificación entre la ley divina y la de orden natural-racional parecía constatarse en las obras de ilustres pensadores como Atenágoras, Clemente de Alejandría, Orígenes, Tertuliano o Lactancio (a través del cual hemos recibido el tercer libro del De re publica ciceroniano). Sin embargo, a excepción de san Ambrosio, ninguno de estos autores parecía ser consciente del riesgo que asumían al interpretar la citada carta paulina como un símbolo de la compatibilidad entre los postulados cristianos y el iusnaturalismo racionalista, dado que, si se aceptaba la existencia de un Derecho natural que sin necesidad de ser revelado, como era el caso de la ley mosaica, pudiera servir como medio para lograr la salvación de los hombres, también supondría un serio obstáculo contra la redención, la gracia divina y, por ende, el advenimiento de Cristo. ${ }^{10}$

En definitiva, a través de la vía iusnaturalista, el racionalismo había logrado acceder a la doctrina cristiana, a pesar de que inicialmente fueran conceptos antitéticos.

Anticipando el dilema que ulteriormente se le plantearía a su discípulo, san Ambrosio, se formuló una cuestión clave en el devenir de los siglos a la que la doctrina anterior no había hallado respuesta: dando por supuesta la existencia de una ley innata a la naturaleza humana, ¿qué necesidad había de una ley positiva revelada? La respuesta a esta interrogante, es decir, que, habida cuenta de la manifiesta inobservancia de la norma natural por parte de los hombres, se hacía precisa la concurrencia de una regla positiva de carácter divino, no debió - a nuestro juicio — ser muy satisfactoria, sobre todo si se considera que S. Agustín, en su etapa pre-pelagiana, seguía confudiendo la lex aeterna con la lex naturalis. ${ }^{11}$

$\mathrm{Si}$ al pensamiento agustiniano debiera calificársele con un adjetivo, éste sería, atendiendo a la mayoría de los estudios iusfilosóficos realizados sobre este tema, el de «inseguro»; ello explicaría el hecho de que gran parte de la actual corriente iusnaturalista católica no conciba que la obra de un autor clave en la fundamentación histórica del Derecho natural cristiano pueda adolecer de graves incongruencias a raíz de su polémica con Pelagio, concretamente en De Civitate Dei, donde abjuraba del iusnaturalismo para profesar un ferviente voluntarismo. ${ }^{2}$ En este sentido, no creemos incorrecto ubicar en el año 411 el punto de inflexión del proceso de transición hacia el voluntarismo. Con anterioridad a esta fecha - marcada por el debate pelagiano- pueden observarse algunas afirmaciones de corte iusnaturalista, como en De Libero Arbitrio, donde la validez de la lex tem-

10 G. Fassò, Cristianesimo e società, Milán, Giuffrè, 1969, pp. 17 y ss.; Storia della Filosofia del Diritto (I), pp. 191-192, en donde este autor ilustra dicho planteamiento utilizando un fragmento de san Juan Crisóstomo (In Episcolam ad romanos homilia, V, 5). Respecto a las epístolas paulinas y el cuarto evangelio, vid. N. Abbagnano, Storia della filosofia (I), Turín, U.T.E.T., 1982, p. 260; B. Leoni, Lezioni di Filosofia del Diritto, Pavía-Milán, Viscontea, 1957, p. 22.

11 Fassò, «Sant'Agostino e il giusnaturalismo cristiano», pp. 752-755; La legge della ragione, pp. 37-42; Storia della Filosofia del Diritto (I), pp. 196-199; Il diritto naturale, Turín, E.R.I., 1972 (2. ${ }^{a}$ ed.), p. 35.

12 Cotta, o.c., p. 18; igualmente, tanto Del Vecchio, o.c., p. 45, como F.B. Cicala, Filosofia e diritto (II), pp. 229 y ss.; G. Ambrosetti, Diritto naturale cristiano. Lineamenti storici, Roma, Studium, 1964, pp. 58-84; W. Cesarini Sforza, Storia della Filosofia del Diritto in compendio, Pisa, Vallerini, 1939 (2. ${ }^{a}$ ed.); «Cristianesimo e comunismo», en Vecchie e muove pagine di filosofia, storia e diritto (I), Milán, Giuffrè, 1967, p. 364. Todos ellos, cuando se refieren al concepto de bien y mal en san Agustín, sólo hacen mención a De Civitate Dei, escrito en su fase voluntarista. Cierta analogía respecto a la tesis de Guido Fassò presenta la postura de P. Alfaric. L'evolution intellectuelle de Saint Augustin. I, Du Manichéisme au Néoplatonisme, París, E. Norry, 1918, donde se afirma que, durante su juventud. S. Agustín era más platónico que cristiano. 
poralis dependía de su adecuación a la lex aeterna (que es al mismo tiempo de naturaleza racional), ${ }^{13}$ lo cual no implicaría aceptar - como apunta Opocher- que el Derecho natural cumpliera para el Estagirita una función mediadora entre la lex aeterna y la lex humana, ya que, de ser así, se estaría avanzando con varios siglos de antelación la división tomista entre lex aeterna, lex naturalis y lex humana. ${ }^{14}$

El iusnaturalismo agustiniano alcanzó sus mayores cotas en Contra Faustum Manicheum, obra en la que, al abordar el concepto de pecado, afrontaba a su vez el de ley eterna, definiéndola como «ratio divina vel voluntas Dei». ${ }^{15} \mathrm{La}$ conjunción latina vel ( $o$ en castellano) ofrecía una lectura tanto racionalista como voluntarista del Derecho natural.

Sin embargo, en el año 411 Pelagio advertía a san Agustín sobre su manifiesta tergiversación de la epístola paulina a los romanos, puesto que, si se le reconocía a la razón humana la posibilidad de conocer la Verdad suprema, la ley divina revelada carecería de sentido y, por consiguiente, sería factible incluso dudar de los dogmas de la fe cristiana. A partir de esta fecha, indica Fassò, se produciría la total conversión agustiniana al voluntarismo, la redención de los hombres sólo podría producirse a través de la fe, que es donde se disolverá el Derecho natural. En este punto es precisamente donde este autor ha extraido la conclusión más relevante y controvertida: «messo sull'avviso da Pelagio, Sant'Agostino si è accorto che il giusnaturalismo è incompatibile con il cristianesimo», produciéndose en la obra agustiniana un efecto inverso al de otros pensadores modernos, que, abandonando una ética voluntarista, fueron gradualmente desplazándose hacia el iusnaturalismo racionalista.

De este modo, quedarían esbozadas las dos grandes coordenadas que guiarían la moral del medievo, representadas por los intelectualistas (los cuales sostenían el origen racional del Derecho natural) y por los voluntaristas (quienes, al contrario, estimaban que aquél derivaba de la voluntad de Dios). ${ }^{16}$

\section{HUMANISMO, MODERNISMO Y RACIONALISMO ÉTICO EN SANTO TOMÁS}

Si se efectuase un repaso sumario a lo que hasta el momento ha sido objeto de exposición, comprobaríamos cómo aquella ética racionalista greco-romana repudiada en los primeros albores del cristianismo, revalorizada por la patrística y denostada en los escritos pos-pelagianos de san

13 San Agustín, De libero arbitrio, en Obras (vol. III), versión, introducción y notas de V. Capanaga, E. Seijas, E. Cuevas, M. Martínez y M. Lanseros, Madrid, B.A.C., 1971 (4. ${ }^{a}$ ed.), I, 5 (11) (Patr. Lat. XXXII, 1227); I, 6 (15) (Patr: Lat. XXXII, 1238); De diversis quaestionibus, en Obras (vol. IX), versión, introducción y notas de V. Capanaga y G. Erce. Madrid, B.A.C., Madrid, 1973 (3, ㄹ ed.), LIII, 2 (Patr. Lat. XL, 36), donde S. Agustín explica cómo la lex aeterna se reveIa al alma racional humana como lex naturalis (la cursiva es de Guido Fassò).

14 E. Opocher, E., o.c., p. 91, cfi: Fassò, La legge della ragione, p. 41.

15 San Agustín, Contra Faustum manichaeum, en Obras (vol. XXXI), versión, introducción y notas de P. de Luis, M.M. Campelo, T.C. Madrid y J. Oroz, Madrid, B.A.C., 1993, XXII, 27.

16 Fassò, «Sant: Agostino e il giusnaturalismo cristiano», p. 759; La legge della ragione, pp. 46-47; Il diritto naturale, p. 36. Destacando la importancia que en la polémica con Pelagio desempeñó De libero arbitrio, vid. F. De Capitani, $I l$ «De libero arbitrio» di Sant'Agostino, Milán, Vita e Pensiero, Pubblicazioni della Università Cattolica del Sacro Cuore, 1987. pp. 210-217. Resaltando la trascendencia de las epístolas paulinas para la comprensión del concepto agustiniano de Derecho natural, vid. Badillo O'Farrell. P.J., Presupuestos teológicos de la filosofía jurídica agustiniana, Sevilla, Universidad de Sevilla, 1975, pp. 37 y ss. 
Agustín, podría haberse desvanecido sin llegar a calar en el iusnaturalismo laico de Grocio, ni en las revolucionarias teorías de la Ilustración, de no existir un eslabón intermedio que permitiese, a través de la Edad Media, el tránsito de la Filosofía del Derecho greco-romana al mundo contemporáneo. Esa piedra angular del proceso evolutivo iusnaturalista-racionalista está encarnada fundamentalmente en la figura y la obra de santo Tomás de Aquino. ${ }^{17}$

A este respecto, podrían destacarse dos líneas directrices del pensamiento tomista absolutamente relevantes: de un lado, la «modernidad» del pensamiento iusfilosófico del Aquinate, de otro, el «carácter humanista y racional» de la ética tomista.

A pesar de que al discípulo de san Alberto Magno le ha sido recriminado habitualmente su oculto deseo de poner la razón al servicio de la religión católica (como dique de contención contra el poder estatal), lo cierto es que la esencia subjetivista y antropocéntrica de la moral tomista permitiría prescindir del superficial revestimiento teológico que impregna su principal obra, la Summa theologiae. Complementando esta aserción, santo Tomás propugnaba la autonomía de la lex naturalis frente a la lex aeterna, sin que ello fuera óbice para reconocer la superioridad de la segunda como producto directo de la razón divina, participando también en ella el ser humano en cuanto criatura racional. Por consiguiente, la ley natural no era copia imperfecta de la ley eterna, sino parte de ésta que irradiaba de la razón humana, siendo, por tanto, cuantitativamente inferior a la ley eterna, aunque cualitativamente idéntica. ${ }^{18}$

De este paralelismo entre la lex aeterna y la lex naturalis, puede inferirse la autonomía de la última, pues sería incongruente que la voluntad divina pudiera estar en contra de una norma que indirectamente dimana de ella, constituyendo esta circunstancia un indiscutible precedente para el iusnaturalismo laico de Grocio, que proclamaría la célebre frase «etiamsi daremus [...] non esse Deum».

Tema de constantes controversias había sido también la delimitación del contenido material de la ley natural, sobre todo si se considera la trascendencia que la solución de esta incógnita supone para la aclaración de las cuestiones más relevantes suscitadas en el seno del binomio lex naturalislex humana, de ahí que, aunque el Aquinate no siempre niegue la validez a las leyes injustas, sí parece condicionar el valor moral a su conformidad con la ley natural de la que proviene, y, por ello, a la recta ratio. ${ }^{19}$

Ahora bien: ¿cuáles son esos principios de Derecho natural que toda ley positiva debería observar para no incurrir en una corruptio legis?; y, en el supuesto de que existiesen, ¿serían siempre válidos, eternos e inmutables? A este respecto cabría señalar que santo Tomás consideraba ahistóricamente tan sólo a aquellos «principios supremos o primarios» que, plasmados en la fórmula «bonum faciendum, malum vitandum», sean interpretados formalmente, porque, si bien es cierto

17 Sobre la continuidad del iusnaturalismo racionalista a través de santo Tomás, vid. G. Fassò, «San Tommaso giurista laico?», en Scritti di Filosofia del Diritto (Y), p. 381; La legge della ragione, p. 70; Il diritto naturale, pp. 41-42; A. Passerin D'Entrèves, Riccardo Hooker: Contributo alla teoria e alla storia del diritto naturale. Memorie dell'Istituto Giuridico della R. Università di Torino, 1932; Scritti politici, Boplonia. Zanicchelli, 1946, pp. I-XXXV [trad. cast., C. Folache Zapata, Caracas, Instituto de Estudios Políticos, Universidad Central de Venezuela, 1962]: P. Piovani, Giusnaturalismo ed etica moderna, Bari, Laterza, 1961. pp. 90-91.

18 Santo Tomás, Summa theologiae, versión, introducción y notas de F. Barbado Viejo, Madrid, B.A.C., 1966, 1. 2., q. 91, a. 2; Fassò, Storia della Filosofia del Diritto (I), p. 259.

19 Santo Tomás, Summa theologiae, 1. 2., q. 95, a. 2; para un concepto más amplio de validez normativa, ibídem, 1.2., q. 96 , a. 4 . 
que en la obra del Doctor Angélico no se explica con claridad qué se entiende por «bien», parece innegable que sí se facilita la forma o procedimiento a través de los cuales el sujeto podría meditar y resolver los problemas morales o jurídicos que ocasionalmente pudieran encontrarse: la conducta humana debe ser racional. ${ }^{20}$

En la racionalidad de la ley orientada al bien común y la concepción laica de la justicia se percibe el influjo directo de Aristóteles. En efecto, para el Aquinate la sociedad es una agrupación de hombres que viven en el mundo físico, histórico y que la razón se encarga de dirigir al bien común; en cambio, la «ordinatio ad unum» 0 «comunión de los santos» debe interpretarse en sentido metafórico. ${ }^{21}$

En suma, a nuestro juicio, con la Summa theologiae se logra un perfecto equilibrio entre la exaltación de los principios divinos y la protección de los valores humanos. Lejos de sumergir indefectiblemente al hombre en el orden universal medieval que se orienta ad unum, santo Tomás de Aquino le confirió una esfera autónoma, lo cual le hizo distanciarse de posturas teocéntricas como la de san Agustín. A partir de entonces quedaría expedita la vía de la controversia entre los voluntaristas (encabezados por Scoto y Ockham) y los intelectualistas (afines a la versión iusnaturalista propugnada por santo Tomás). ${ }^{22}$

Fernando H. Llano Alonso

Dpto. Filosofía del Derecho, Moral y

Política

Facultad de Derecho.

Universidad de Sevilla

Avda. Cid S/N

E- 41004 SEVILLA

20 G. Fassò, «ll diritto naturale in Italia negli ultimi dieci anni», en Scritti di Filosofia del Diritto (I), p. 260; Il diritto naturale,pp. 40-41; cfr: Ambrosetti, Lezioni di Filosofia del Diritto, p. 196; A. Pigliaru, «Il concetto di legge secondo san Tommaso», Rivista Internazionale di Filosofia del Diritto, II (1957), p. 446.

21 Santo Tomás, Summa theologiae, 3, q. 8, a. 1; G. Fassò, «Giustizia, carità e filantropia», en Scritti di Filosofia del Diritto (I), p. 436; La legge della ragione, p. 90.

22 S. Cotta, Il concetto di legge nella Summa theologiae di San Tommaso d'Aquino, Turín, Giappichelli, 1955, p. 17; Fassò, «San Tommaso giurista laico?», pp. 383-386; L. Legaz y Lacambra, Filosofia del Derecho, Barcelona, Bosch, 1953, p. 81 . 